\title{
Larga vida a la tragedia: ensayo sobre la tragedia y la revolución
}

\section{Long Live the Tragedy: Essay on Tragedy and Revolution}

\author{
ÁLVARO RAMOS COLÁS*
}

\begin{abstract}
Resumen: En este ensayo se intenta explorar la relación entre tragedia, política y revolución, en especial los aportes de la escuela culturalista británica. En respuesta a la tesis de la muerte de la tragedia (sostenida por Steiner, entre otros), Raymond Williams defiende la necesidad de la revolución como arma política y la importancia de la tragedia para su consecución. Terry Eagleton asume la necesidad de la revolución y la importancia de la tragedia, pero recurre a las categorías lacanianas para marcar diferencias con su maestro Williams. Clark aporta una visión personal y crítica respecto a ambos.

Palabras clave: tragedia, política, ética, revolución, marxismo, modernidad.
\end{abstract}

\begin{abstract}
In this essay, I explore the relation between tragedy, politics and revolution, specially through the British culturalist thought. Raymond Williams, responding the death of the tragedy thesis (Steiner among others), defends the necessity of revolution as a political means, and the importance of tragedy to carry it out. Terry Eagleton assumes the necessity of revolution and the importance of tragedy, but disagree with him about his humanist optimism. The turn Eagleton proposes is based upon the three lacanian categories. Clark's position lays somewhere between Williams and Eagleton, since he is able to sustain a critical approach to both.
\end{abstract}

Keywords: tragedy, politics, revolution, ethics, Marxism, modernity.

\section{Introducción}

La relación entre política y tragedia ${ }^{1}$ no es del todo evidente si comparamos lo que se entiende normalmente por ambos conceptos. Realmente, su relación empezó a volverse más clara en 1961 con la publicación de un influyente trabajo de George Steiner: The Death of

Recibido: 13/06/2017. Aceptado: 11/01/2019.

* Graduado en Filosofía y Máster en Filosofía Teórica y Práctica por la U.N.E.D. En la actualidad realiza en la U.N.E.D. sus estudios de doctorado en el programa de filosofía. Sus líneas de investigación son, entre otras, las interpretaciones del fin del capitalismo y la tragedia y sus relaciones político-filosóficas. Recientemente ha publicado artículos sobre ambos temas como, por ejemplo, "Ciudadano vs. consumidor: Significado del consumo en el postcapitalismo de W. Streeck", Oxímora. Revista Internacional de Ética y Política, enero-junio 2019, n 14,pp.91-108. Aramos177@alumno.uned.es

1 Un texto imprescindible para cualquiera interesado en introducirse en el estudio de la tragedia (y del que yo he extraído innumerables sugerencias y referencias bibliográficas) es DEL CASTILLO, R. (2014). "Un filósofo con mano izquierda.” En CRITCHLEY, S. Tragedia y modernidad. Madrid: Trotta. 
Tragedy y, especialmente, gracias a la profunda crítica del mismo que Raymond Williams llevó a cabo en Modern Tragedy (1966). Para Steiner, la tragedia no es posible después del racionalismo del XVII y de toda la historia posterior, dado que ésta requiere «la intolerable carga de la presencia de Dios» (Steiner, 1978, 353); en consecuencia, si Dios empezó a diluirse por el empuje de Newton, Descartes, Voltaire, etc., la tragedia siguió irremediablemente la misma suerte en un mundo que ya empezaba a desencantarse a pasos agigantados. La obra trágica no deja de estar concebida como una representación escénica de una mitología vivida, es decir, de un modo de ver la vida:

La tragedia es irreparable [...] nos dice que las esferas de la razón, del orden y de la justicia están terriblemente limitadas y que ningún progreso técnico o científico podrá ampliar su relevancia. Dentro y fuera del hombre se encuentra l'autre, la "otredad" del mundo. Llamadlo como queráis: un Dios malo y escondido, un destino ciego, los requerimientos del infierno, o la furia bruta de nuestra sangre animal [...] Se ríe de nosotros y nos destruye. En extrañas -aunque concretas-circunstancias, después de destruirnos, nos proporciona un incomprensible reposo (Steiner, 1978, 8-9). ${ }^{2}$

Esa maldición que decide la suerte inapelablemente es lo que separa nuestra época de los tiempos de la tragedia. De hecho, a menudo se ha interpretado la modernidad como el proceso en el que esa fuerza heterónoma va siendo puesta en cuestión hasta llegar a la consecución del hombre totalmente autónomo.

Steiner, como también J. P. Vernant (Tragedy and Myth in Ancient Greece, 1981), pertenece a ese grupo de intelectuales que opinan que la tragedia no se circunscribe a una época determinada, aunque en ningún caso, su historia es continua, al no darse siempre las características históricas, culturales, sociales, etc. necesarias para su existencia. En el caso de Steiner el arco temporal -discontinuo- se trazaría desde la tragedia ática hasta el teatro de Shakespeare. La tesis de Vernant, en cambio, limita lo trágico a la Atenas clásica, ya que, según él, solo en aquellas circunstancias sociopolíticas se reproducen las tensiones necesarias para su surgimiento. La contraposición entre lo humano y lo divino, entre lo político encarnado en el ciudadano y lo religioso de la mitología presente en las creencias de los habitantes de la pólis, son las tensiones a las que el estudioso francés hace referencia. Ahora bien, estas actitudes escépticas respecto a la pervivencia de la tragedia han sido contestadas por numerosos estudiosos de la materia, como es el caso de los culturalistas de la escuela británica marxista de la segunda mitad del siglo Xx. El presente ensayo versará sobre dos de sus máximos representantes y prestará especial atención a los debates y conceptos claves que entre ellos se establecen.

\section{Tragedia y revolución}

La primera respuesta de la escuela culturalista al texto de Steiner es la del crítico galés R. Williams, el cual se opone a cualquier visión que implique el fin de dicho género literario. Williams no cree que la tragedia sea algo "objetivo", algo con unas características deter-

2 Todas las traducciones de los originales son propias. 
minadas y que, comparándolas con el texto dramático, podamos verificar su autenticidad o falsedad. No podemos establecer una definición exacta y concreta, como intenta con relativo poco éxito Steiner - afirma Williams en Modern Tragedy -, sino que «se llega a la tragedia a través de muchos caminos distintos. Es una experiencia inmediata, un cuerpo literario, un conflicto teórico, una cuestión académica. Este libro parte de mi experiencia vital que es la encrucijada de esos caminos» (Williams, 1969, 13). Así las cosas, la tragedia tiene que ver con la vida, pero no pensada en abstracto, sino con la vida particular de todos y cada uno de nosotros. No estamos hablando de una categoría de la ciencia literaria, sino de una parte de nuestras vidas. Desde este posicionamiento, no resulta difícil incluir el dolor de tantas personas anónimas dentro de la categoría de la tragedia, y subraya algo que la posición de Steiner no contempla: que esas "tragedias cotidianas" pueden ser algo muy triste e injusto, pero no por la intervención del "destino" o el capricho de los dioses.

Williams critica, en resumen, el elitismo trágico y el alejamiento de la realidad de Steiner, pero se le podría objetar que igualar tragedia y sufrimiento, como hace Williams, difumina su significado. La propuesta del galés es una aproximación alternativa: en vez de partir de la teoría para explicar la realidad, buscamos lo que de trágico podamos encontrar en la realidad para construir un mundo más justo en el que vivir.

Esta idea puede parecer chocante, ya que la tragedia ha sido considerada $-\mathrm{y}$ sigue siéndolo a menudo -como una cuestión alejada de lo cotidiano, ligada a seres de un cierto rango, pertenecientes a un pasado mítico y que, en definitiva, no pueden ser entendidos como portadores de valores actuales, sean estos políticos o de cualquier otro tipo. Algunos teóricos, eso sí, han extraído consecuencias éticas relacionadas en gran medida con algunos de los profundos valores que se le otorgan asiduamente (el destino-libertad, el honor-caída, la maldición-responsabilidad, el error trágico, etc.). La propuesta de Williams consiste en dotar de contenido político este arte -independientemente de la época en la que sea producido-, y no un contenido cualquiera, sino uno radical o, dicho con sus propias palabras, un contenido revolucionario:

Una sociedad necesitada de una revolución es aquélla en la que la incorporación de todas las personas, como seres humanos completos, es en la práctica imposible sin un cambio en sus formas fundamentales constitutivas. Cualquier tipo de "incorporación" parcial -como votantes, como asalariados, como receptores de una educación, de una protección legal, de servicios sociales, etc.- son ganancias humanas, pero no bastan por sí mismas para hacernos totalmente miembros de una sociedad sin clases. La realidad de la completa pertenencia es la capacidad de dirigir una sociedad mediante la mutua responsabilidad y cooperación sobre la base de una igualdad social total. [...] La revolución sigue siendo necesaria no sólo porque algunos la deseen, sino porque no puede haber orden humano mientras siga habiendo personas excluidas en la práctica. $[\ldots]$

[...] Esta idea de "redención total de la humanidad" tiene como último objetivo la resolución y el orden, pero en el mundo real esta perspectiva es indefectiblemente trágica. Nace de la pena y del terror: de la percepción radical del desorden que es la negación de la humanidad de algunas personas y por tanto de la negación de la idea de humanidad en sí misma. Nace del sufrimiento de hombres reales [...] Nace 
de una experiencia del mal que se hace más intolerable por la convicción de que no es inevitable. (Williams, 1969, 76-77)

La revolución, irónicamente y contra lo que la tradición liberal opina de ella, es un paso del desorden a una situación de mayor orden, de un caos absoluto a uno menor, teniendo siempre como objetivo la consecución de un orden total, algo así como una armonía social completa. Desde una óptica marxista como la de Williams, no cabe duda que el mundo en el que vivimos es profundamente injusto, formado en lo político por democracias liberales que sustentan ideológicamente los intereses de las clases dominantes. Por eso, a pesar de que la revolución normalmente implique desorden, violencia y sufrimiento, si de verdad se quiere llegar a una situación global más justa, debe cruzarse el umbral de la revolución y pasar del orden ficticio del capital a otro más auténtico (Williams, 1969, 65). La propuesta del crítico británico demanda un orden del que todos los seres humanos sean parte integrante y, además, protagonistas. El objetivo de Williams, en resumen, es la incorporación de todas las personas dentro de los márgenes de la justicia, y eso implica la igualdad de "derechos" en un sentido amplio. Sólo en esta situación podrán ser considerados "seres humanos completos"; nos encontramos ante un momento utópico en el cual ya no será necesaria revolución alguna, al no haber sufrimiento evitable, o lo que es lo mismo, tragedia.

El gran valor de la tragedia para Williams, como se deduce de lo expuesto hasta aquí, es que nos muestra la frontera entre el orden y el desorden, entre lo justo y lo injusto. El binomio orden/desorden lo marca, pues, el hecho de que exista alguna injusticia evitable. Y el sentimiento que nos invade -o debería- ante tales injusticias es, precisamente, el de la pena y terror ante el desconsuelo de los que padecen la injusticia. El modo de mostrar la injusticia y el dolor es, de este modo, necesario para la revolución, y eso lo entendemos en gran medida, según el crítico británico, gracias a la tragedia como arte. Ibsen, por ejemplo, nos hace sentir en Casa de muñecas el sufrimiento de algunos individuos de la pequeña burguesía escandinava finisecular, o lo que es lo mismo, cómo una sociedad con todo a favor para desarrollar las mejores facultades de las personas, se torna en una jaula de barrotes de oro. En este sentido, obras como las de Ibsen (aunque también las de a A. Miller), nos permiten apreciar ese callejón sin salida al que nos conducen el liberalismo y un humanismo ideologizado (Williams, 1969, 106).

Otra enseñanza que nos ofrece la tragedia, según Williams, es que nos habla acerca de nosotros mismos desde muy distintos puntos de vista. Gracias a Strindberg, por ejemplo, entendemos cómo muchas personas luchan contra sí mismas. En el mejor de los casos, en estas manifestaciones de la tragedia la sociedad es arbitraria, y las formas que llega a adoptar se siguen de la suma de deseos e impulsos de los individuos. Strindberg, en opinión de Williams, nos revela que la sociedad es el sumatorio de los deseos de cada uno de sus integrantes, lo que conlleva un conflicto irresoluble. La lucha contra nosotros mismos es, en consecuencia, también contra todos los demás y, por supuesto, autodestructiva, dando como resultado una experiencia vital de disputa desesperada, continua y sin posibilidad de solución. Lo que Strindberg nos hace sentir, según Williams, es la de la ausencia de sentido más allá de la convención, una suerte de ley del más fuerte donde sobrevivirán sólo los que tienen mayor capacidad de adaptación al medio y los que son capaces de transformar sus impulsos autodestructivos en capacidades para dominar al resto $(1969,110)$. Chekhov, por su 
parte, relativizará las grandes narrativas que pretendían desde el idealismo o el materialismo dar una explicación total de la naturaleza humana y de la realidad en que se desenvuelve. Williams ve en la obra del ruso una maduración del realismo que desemboca en una situación donde ya no luchamos los unos contra los otros, sino que se conforma cada vez más fragmentada y atomizada, una realidad descompuesta e ilusoria, cuyos individuos, utilizando la metáfora leibitziana, son mónadas sin puertas ni ventanas. De la descomposición del realismo, que el mismo Chekhov simboliza, surge la aterradora sombra la imposibilidad de la comunicación entre seres humanos. De esas ruinas de la comunicación, que lo son también de una posible sociedad armónica, surgirán propuestas como la de Pirandello, posteriormente las de Beckett e Ionesco y, en cierta medida, las de Camus y Sartre.

En resumen, para Williams lo que conecta lo general con lo particular en la tragedia es el sufrimiento, y éste, en gran medida, es evitable, al ser el fruto de unas estructuras socioeconómicas radicalmente injustas. Lo que la tragedia, en tanto que obra literaria, nos enseña son representaciones e interpretaciones de ese sufrimiento. En cierto modo, siguiendo la interpretación del crítico galés, podría afirmarse que deja entrever las ideologías de la época y de quien las produce, y, por eso, gran parte de su labor en Modern Tragedy consiste en intentar entender las obras trágicas a la luz de su época, sus autores y las corrientes de pensamiento. Reconocer las raíces del sufrimiento en otras épocas y culturas no sólo ayuda a no dejar caer en el olvido a las víctimas de la historia -que también, por supuesto-, sino que, sobre todo, nos sensibilizará acerca del dolor que una situación social injusta puede provocar.

Es importante insistir en que la mayor discrepancia de Williams frente a Steiner y los defensores de la tesis de la muerte de la tragedia, es que ésta no es portadora de lecciones inmemoriales que encarnan el núcleo más profundo de una esencia humana inmutable. Para Williams, este cambio es posible y necesario, mientras que, para Steiner, por el contrario, cualquier intento de control del orden social en pro de uno más justo es fútil, ya que precisamente esas fuerzas abisales, que definen al ser humano, tarde o temprano se harán con el control de la situación. ${ }^{3}$

\section{La tragedia y el chivo expiatorio}

La posición de Eagleton respecto a la tragedia es, en primer lugar, crítica con los teóricos de izquierda que no han sabido mirar más allá de los lugares comunes que los intelectuales como Steiner han fomentado (Eagleton, 2003, p. XII). Desde las posiciones progresistas se ha ignorado la tragedia por considerarla religiosa, trascendental, retardataria, oscura, elitista, etc. Pero Eagleton también critica, como no puede ser de otra manera, a los que defienden esas teorías tan exitosas y que prácticamente han monopolizado la reflexión al respecto. De hecho, su última intención en Sweet Violence es presentar batalla ideológica a sus adversarios políticos donde antes sólo ellos especulaban. Eagleton adopta una posición intermedia entre los radicales de izquierda y los esencialistas, es decir, beligerante con ambos bandos. No es tarea fácil, pero Eagleton cuenta con el ejemplo de su maestro R. Williams, aunque,

3 En una obra posterior, El castillo de Barbazul, Steiner defiende exactamente la tesis de la imposibilidad de "progreso" tal y como lo entendemos en occidente desde la Ilustración. En ese texto expone que las sociedades desarrolladas son incapaces de controlar fuerzas internas altamente autodestructivas y que nos empujarán a una decadencia paulatina para acabar con esas sociedades. 
como veremos más adelante, también se muestra crítico con algunos de sus postulados. Esa posición intermedia consiste en situarse en un espacio entre lo histórico y lo esencial, y que Eagleton encontrará en lo transhistórico, entendiendo por ello la naturaleza humana; con esto no se refiere a lo que nos distingue como especie biológica -limitarse a eso sería, en el fondo, otra expresión del viejo esencialismo-, sino más bien lo que como especie nos limita materialmente y que, por tanto, debe tener repercusiones políticas. Es, además, en ese terreno intermedio donde también radica su acción política y ética, puesto que, si el sufrimiento y el dolor son algo propio de todo ser humano, entonces todos nos podemos ver envueltos en algún tipo de tragedia y, por tanto, la tragedia como arte nos puede hacer conscientes de nuestra propia debilidad y finitud (Eagleton, 2003, p. XV). Es crucial recalcar intención política del texto de Eagleton y, en ese sentido, es necesario entender esa restricción material como la fuente de un posible poder, al ser donde nuestras necesidades se originan; sólo averiguando nuestras limitaciones será posible liberarnos de ellas.

La primera y más evidente restricción será la de nuestra corporeidad, el hecho incontrovertible de ser individuos de carne y hueso. Este punto de partida pretende rebatir uno de los prejuicios instaurados por la modernidad, el de la supremacía absoluta de la conciencia frente a la carne. Con esta asunción no pretende negar Eagleton que seamos conciencia, lo que niega es que lo que nos defina sea exclusivamente la conciencia. Somos carne en el sentido más material de la expresión. Pero lo que interesa subrayar es la importancia política de la relación entre conciencia y corporeidad. Sólo si somos capaces de desmontar todas esas capas de "conciencia" que recubren nuestra naturaleza humana, seremos capaces y políticamente autónomos; sólo si sentimos que el Otro es corpóreo, que siente hambre, frío y alegría como nosotros, es decir, sólo si conseguimos sentir antes de cualquier racionalidad o mediación cultural la "obligación corpórea" que nos une como humanos y que nos define como humanos, sólo así podemos aspirar a una ética y política revolucionaria (Eagleton, 2003, 287). Todos podemos ser tristes protagonistas de la tragedia, no sólo los héroes y los príncipes: a esto se referirá con la "democratización de la tragedia".

Es importante insistir en que esta capacidad para captar el sufrimiento de nuestros congéneres hunde sus raíces en las tesis de Williams, ${ }^{4}$ pero Eagleton no termina de aceptar totalmente que la identificación con el dolor ajeno sea suficiente para desencadenar la revolución. En Modern Tragedy se desarrollan las ideas sobre lo que es la tragedia y de la relación de ésta con la toma de conciencia de la injusticia, pero no se explicita cómo se llega a la acción política. En una representación, por ejemplo, de Muerte de un viajante nos puede conmover el sufrimiento y la frustración de Willy Loman, pero, ¿implica esto que el espectador se replantee sus posiciones políticas? Después de todo, cuando se asiste a una representación teatral, por mucho que pueda afectarnos, somos conscientes de estar presenciando un espectáculo, es decir, una ficción que imita la vida, pero que no deja de ser ficción.

Para Eagleton, la teoría de la tragedia de Williams confía en exceso en la capacidad del género humano para sublevarse ante la injusticia. Por eso da la impresión de que cuando escribe su Sweet Violence -casi cuarenta años después de la publicación de Modern Tragedy-, busca algo que le lleve más allá de esa confianza que, a la luz de esos cuarenta años

4 Williams fue profesor del joven Eagleton, ejerciendo una influencia decisiva en su formación. Posteriormente, Eagleton se aproximó a Althusser, para al cabo de los años acercarse de nuevo a su maestro. 
transcurridos, parece difícil de mantener. Ese algo que necesita para explicar la relación entre las pasiones de la tragedia y los efectos que ésta puede propiciar, estará relacionado con las tres categorías lacanianas: lo imaginario, lo simbólico y lo Real. Los conflictos en el orden simbólico -lucha política, traición sexual, etc.- que nos invitan a una identificación imaginaria se corresponden, expresado en términos lacanianos, con las tesis de Williams, pero Eagleton introduce lo "irracional", esto es, la sombra de lo Real y el horror que produce su negatividad. Lo Real es lo aterrador, lo inefable, lo que escapa a la racionalización, es decir, a lo simbólico. No es lo contrario de lo humano, sino lo "salvaje", lo no domesticado que mora también en todos nosotros. Es más, toda ley simbólica, tal y como entiende Eagleton a Lacan, "esconde en su interior [...] lo Real, esa condición en que somos indigentes, desmembrados, arrojados al abismo de la ausencia de designación, aplastados por el sinsentido que nos es más cercano que la respiración" (Eagleton, 2010, 206). Esto implica que dentro del mismo orden simbólico podemos encontrar el punto de apoyo para derrocarlo, que no es otra cosa que una reconfiguración de la realidad (Eagleton, 2010,261). Ahora bien, lo Real es justo lo contrario a una ficción con la que reconfortarnos mientras esperamos la consecución de un mundo justo, es algo que nos corroe, una especie de sed insaciable, un incómodo deseo siempre presente que nos conforma. Ante esta incomodidad podemos intentar reconciliarnos con los demás y con nosotros mismos mediante fábulas que intenten acallar ese deseo (reconciliándonos con lo simbólico), pero también cabe la posibilidad de aceptar esa negatividad, de no abandonar nuestro deseo. ${ }^{5}$ Los tres registros se necesitan para sostenerse, pero el que normalmente ha sido acallado en la modernidad es el de lo Real ya que sus sombras amenazan gravemente a las luces de la Razón.

Esta es la principal divergencia respecto de Williams, a saber: Eagleton nos insta a reconocer, si se quiere hacer una política verdaderamente revolucionaria, nuestra parte oscura y no racionalizable; si no lo hacemos, caeríamos en un optimismo infundado y destinado al fracaso. Se distancia así de ese humanismo socialista del maestro que le parece demasiado afirmativo para explicar tantas atrocidades y tanta maldad inmanente al ser humano. Por eso acude a Lacan. Si el humanismo de Williams nos empuja a defender la inclusión de todos los individuos en base a su bondad innata y a su indefensión frente a los poderes socioeconómicos externos, el escepticismo de Eagleton acerca del humanismo nos indica que, si queremos salir del hermetismo del yo que siente pena por los otros -el individuo es el sujeto y el otro es un mero objeto de compasión-, entonces debemos sentir simpatía hacia lo que de monstruoso hay en él.

Es, sin duda, una propuesta difícil de aceptar, y más todavía de llevar a cabo, ¿cómo podemos sentir compasión, por ejemplo, por sujetos crueles con los indefensos? En la tradición judeo-cristiana eso se conoce como la ley del amor (Eagleton, 2003, 165). Esta ley no consiste en amar literalmente a todos nuestros congéneres, sino en tratarlos humanamente, es decir, tratarlos de un modo justo, sea quien fuere ese prójimo. A esto se refiere Eagleton con la "identificación imaginaria":

La tragedia encarna las categorías lacanianas: los conflictos en el orden simbólico - litigios políticos, traiciones sexuales, etc. -nos invitan, a través principalmente de

5 “NNo cedas en tu propio deseo!” es, según Eagleton, el imperativo ético de Lacan (Eagleton, 2010, 261). Lacan lo expone en la Ética del psicoanálisis (Lacan, 1990, 381 ss.). 
la compasión, a identificarnos imaginariamente con los sufrimientos de los demás; pero esta identificación es interrumpida por el miedo, o lo que es lo mismo, por la irrupción de lo Real (Eagleton, 2003, p. 164-165).

En consecuencia, la tragedia, por un lado, nos lleva a identificarnos con los sufrimientos ajenos, pero, en opinión de Eagleton, también nos lleva más allá de la mera compasión: el miedo, es decir, lo Real que mora en todos nosotros, extrayendo de ahí consecuencias de profundo calado ético y político:

Solamente las relaciones basadas en el mutuo reconocimiento de lo Real - de lo abyecto instalado en el centro de nuestro ser - podrán prosperar. Lo que ha de ser compartido para superar un mero de reflejo de egos, es lo que nos es extraño a ambos. $\mathrm{Y}$ eso es precisamente lo que se ignora intencionalmente en el mundo de la conciencia y de la civilización. [...] El pilar sobre el que asentar el nuevo orden debe ser, al igual que en Edipo en Colono, lo sucio y lo denigrante (Eagleton, 2003, p. 165).

Ser todos portadores de esa oscuridad de lo Real implica que, independientemente de quién nos encontremos en nuestro camino, le debemos el reconocimiento imaginario en cuanto que humano, en cuanto que Otro, ya que todos, en principio, somos capaces de lo peor y, por consiguiente, somos todos a su vez susceptibles de ser víctimas de la injusticia. ${ }^{6}$

Hasta aquí Eagleton nos ha presentado su idea de tragedia como suceso político y social, ha teorizado sobre aspectos de la naturaleza humana, sobre las relaciones de poder, etc. Pero le queda todavía dar el paso para conseguir establecer la relación de la tragedia en tanto que arte con la tragedia como sufrimiento causado por la injusticia evitable, que es la marca distintiva del modo de entenderla por parte de los culturalistas británicos. Para ello recurre a un elemento que, para él, es el pilar sobre el cual podemos centrarnos para entender la unión de esas dos formas de ver la tragedia.

El concepto es el de scapegoat -cabeza de turco, víctima sacrificial o, en griego clásico, pharmakos-. Esta figura no está presente en todas las tragedias, pero es la que con más fuerza recoge la intuición de que, en ciertas ocasiones, algo debe ser desmembrado o reducido a nada para poder renovar el orden simbólico al que pertenece y al que se enfrenta (Eagleton, 2003, 275 ss.). Sobre él o ella, cae el peso de la culpa de toda la comunidad, y por eso es necesario su sacrificio para la expiación de los males de la colectividad y, de este modo, su supervivencia. Pero, contra lo que podría pensarse en un principio, el chivo expiatorio no tiene que ver exclusivamente con lo individual, con el héroe que paga por su osadía o arrogancia contra el destino y los dioses, o con el príncipe enfermo de poder o lujuria. Sobre él cae el peso de la culpa de toda la comunidad, y, por eso, es necesario su

6 Aquí conviene resaltar las diferencias respecto a una especie de ley del "buenismo" que, según Eagleton, impera en el postmodernismo. Para esta corriente de pensamiento de lo que se trata es de situarse en sintonía con la diferencia cultural y étnica, como ocurre con el multiculturalismo; esta posición acabaría aproximándose al Otro desde una compasión impersonal que nos llevaría a entender la alteridad presuponiendo siempre lo "bueno". Si la diferencia cultural nos impide acceder al lenguaje de la cultura alternativa de un modo completo, y si lo ajeno a nosotros es siempre bueno (de ahí que hable de "buenismo"), entonces no podremos captar las profundidades de lo Real que es lo que Eagleton pretende. 
sacrificio para la expiación de los males comunes, como una maldición necesaria para su supervivencia, un mal ineludible $y$, en cierta medida, justo.

El pharmakos es, al mismo tiempo, sagrado y aterrador, y eso lo acerca a la estructura dual de lo sublime. Pero allí donde lo sublime empobrece la descripción elevándose sobre ella, el pharmakos finiquita el discurso cayendo por debajo, colándose a través de la red del discurso hacia la pura y bruta inefabilidad. [...] Rechazando las afirmaciones del orden simbólico, tales criaturas -los Abraham, Lears, Edipos y Antígonas que los representan- inauguran una ética revolucionaria mediante su modo de afrontar la muerte, de su heroico y tenaz compromiso con un orden de verdad muy distinto, una verdad que revela la negatividad del sujeto antes que legitimar un régimen positivo, y el cual representa, según Jacques Lacan, el terrificante abismo de la Cosa o de lo Real. Estas figuras representan una verdad que el sistema debe reprimir para su correcto funcionamiento [...] Encarnan las contradicciones internas del orden social, y de ese modo representan su propia disfunción. [El rito del pharmakos o víctima sacrificial] identifica que el no-ser es el único camino hacia la identidad verdadera, y aceptar esa disolución puede ser potenciador de la vida antes que su aniquilador. (Eagleton, 2003, 280).

Asumir el concepto del pharmakos trágico implica aceptar sus dos caras: la negatividad total, destructiva y marginal en forma de víctima absoluta, pero también la propiciadora de "un nuevo orden social, fundado en lo Real, en la confesión mutua de finitud y fragilidad, en vez de en fantasías autofabricadas y de infinita flexibilidad" (Eagleton, 2003, 288). La víctima sacrificial implica algo de abyecto, pero es posible "sacralizarla" mediante la reformulación del orden que la mantenía fuera de sus límites. Por consiguiente, no es tanto la revolución trágica como la que soñaba $\mathrm{R}$. Williams, esto es, como una expansión humanista de las fronteras del orden social que incluyera cada vez más personas; lo que propone la teoría política de la tragedia de Eagleton es rescatar a los excluidos como signo de lo que debe ser rehecho desde sus propias raíces. En gran medida, podríamos entender la propuesta de Eagleton como el recorrido del mismo camino que el de Williams pero en sentido contrario: para el galés, la revolución consiste en la expansión de la frontera de lo social para abarcar cada vez más individuos dentro del orden legal justo; en opinión de Eagleton, en cambio, debemos olvidarnos del epicentro de lo social, que es lo que está incluido dentro de las fronteras "normales" con sus valores e instituciones (más o menos lo que se denomina el orden simbólico), para fijar el centro de nuestra nueva concepción ética y política revolucionaria en lo que se encuentra fuera de todo límite, esto es, en los chivos expiatorios que simbolizan lo Real. En cierto modo, usando su propia terminología (Eagleton, 2003, 263), Eagleton es un pensador "demoníaco", de acción, pero también escéptico, lo cual le lleva a dudar del poder de la razón por sí sola para llegar a una sociedad donde la revolución ya no sea necesaria. Sólo así, en opinión de Eagleton, podremos escapar de un sistema radicalmente injusto. Hoy más que nunca, el ser una víctima del sistema (o sea, un pharmakos) no es una cuestión de mala suerte, sino que todos podemos llegar a serlo, debido, como indicábamos más arriba, a nuestra corporalidad común, de estar compuestos del mismo tipo de materia que el resto (Eagleton, 2010, 562). Por eso tiene más sentido que nunca el lema lacaniano de “¡aférrate 
a tu deseo!", entendido como mandamiento político para recordarnos que solo nos podemos conformar con lo mejor, esto es, con un nuevo orden social radicalmente distinto.

El reconocimiento de lo Real en nosotros y en los demás, es decir, asumir que somos verdugos a la par que víctimas sacrificiales, representa una ínfima ventaja: "en lo que respecta a lo Real - dirá Eagleton - el prójimo es aquel que nos acepta en nuestra miseria humana y quien nosotros aceptamos con el mismo espíritu. El vecindario es una práctica y no un enclave físico. Sólo las relaciones basadas en nuestra debilidad mortal tienen la posibilidad de evolucionar más allá de lo narcisista" (Eagleton, 2010, 561, cursivas nuestras).

\section{Revolución y reformismo}

T. J. Clark, historiador y teórico del arte, publicó en 2012 su artículo "Para una izquierda sin futuro" , el cual, a nuestro juicio, es interesante incluirlo por tener una posición original respecto a la política como tragedia y porque, según lo entendemos nosotros, Clark ocupa un lugar intermedio entre Williams y Eagleton al introducir un matiz interesante a las ideas de revolución y tragedia de ambos.

La revolución, para Clark, es lo "infinito", pues contiene lo insondable, que es tanto lo bueno como lo malo (Clark, 2012, 59); esto incluye algo que la izquierda se ha negado a aceptar por motivos ideológicos y de programa, a saber, la propensión a la violencia que reside en el ser humano. Clark asume el papel de abogado del diablo al introducir esta propensión en el interior del ser humano y que, en cierto sentido, se podría a asimilar a lo Real en el sentido en que lo defiende Eagleton. La Ilustración, en la cual hunde sus raíces el proyecto emancipador de gran parte de la izquierda marxista, no niega la maldad del hombre y de la mujer, como muestran, por ejemplo, las alusiones de Kant a la propensión humana al mal; la gran diferencia es que, para Kant en particular y para la Ilustración en general, esa propensión era superable mediante una buena educación, mayor voluntad y renuncia del egoísmo, mientras que para Clark no parece en absoluto superable, sino ontológica. Somos violentos, lo mismo que somos finitos, y por eso siempre estaremos al borde del naufragio, corriendo siempre el riesgo de que nuestra finitud sea borrada de la faz de la tierra por un golpe del destino.

Por eso acude Clark a la tragedia, porque que desde su perspectiva logramos un punto de vista privilegiado de la naturaleza humana (Clark, 2012,51). El hecho de que la tragedia sea pesimista sobre la condición humana nos permite afrontar cuestiones que la política actual deja de lado. No vale, a su juicio, el optimismo infantil del que la izquierda permanece presa, es decir, cerrar los ojos ante la realidad de nuestra condición más violenta para fundamentar una sociedad más justa. Debe ser justamente a la inversa: si se busca la justicia, hay que aceptar que hay algo oscuro dentro de nosotros. Esa concesión, que normalmente provoca un rechazo tajante en la izquierda (Clark, 2012, 52), es la única oportunidad para captar el horror y el sufrimiento sin caer en la tentación de racionalizar este dolor como una evolución

7 En la nota 37 de "Un filósofo con mano izquierda" se Castillo desvela en apenas unas líneas las claves de este original texto, así como interesantes relaciones con otros textos importantes. DEL CASTILLO, R. (2014) "Un filósofo con mano izquierda.” En CRITCHLEY, S. Tragedia y modernidad. Madrid: Trotta, p. 25. 
lógica de los hechos, sino como una verdadera concatenación de catástrofes, violencias y maldades (Clark, 2012, 54).

Esta asunción de la barbarie humana cuestiona el proyecto moderno en general, además de toda la visión del hombre de gran parte de la izquierda. La principal característica de la naturaleza humana, según Clark, sería la propensión a la violencia y, en consecuencia, parece claro que el hecho de mirar al futuro como proyecto social no tiene sentido en sí mismo. Desde que occidente hizo suya la escatología cristiana podríamos decir que nuestra sociedad mira al futuro. Desde luego que ha habido épocas en el que ese futuro o finalidad ha estado más marcado por unas ideologías o por otras, y, por tanto, el télos o utopía de cada una ha variado sensiblemente. La metáfora de Ernst Bloch de la utopía como horizonte hacia el que dirigirse, como guía constante más que un punto concreto al que llegar, parece seguir siendo válida desde el punto de vista de Clark, pero en éste se ve oscurecida precisamente por la falta actual de un horizonte; como hemos visto, a juicio de Clark, la sociedad (dado su origen judeo-cristiano) está orientada al futuro, a un télos, es decir, se define mediante las coordenadas pasado-futuro. El problema reside en que ese télos es tan superficial que hace imposible cualquier esperanza (Clark, 2012,64). Por este motivo el crítico inglés es profundamente escéptico respecto a la utopía, porque no concibe una modernidad sin un télos utópico, sin un proyecto para un cambio radical.

La clave trágica hace que muchas cosas sean posibles e imposibles. Pero quizá lo que es primordial para la izquierda es que la tragedia no espera a algo -algo transformador- para aparecer. La moderna infantilización de la política va acompañada, y quizá depende, de una constante orientación de la política hacia el futuro. Desde luego que la orientación se ha vuelto débil y formularia, y el modelo de programadores y ensambladores de genes es un ejemplo de su fatuidad. Walter Benjamin se horrorizaría ante la forma que tomó realmente su «débil mesianismo» una vez que desaparecieron los poderosos mesías del siglo xx. La utopía de Twitter va de la mano del Tea Party [...] La política, en su forma actual, no es nada sin una nueva modernidad constantemente en perspectiva, sin una alternativa o télos, es decir, sin ninguna otra manera de imaginar las cosas. Esa es la tarea de la izquierda: proporcionar una (Clark, 2012, 64-65).

Pero entonces, ¿debemos abandonar toda esperanza? Esto, para Clark no es posible, porque, como hemos dicho, estamos culturalmente orientados hacia el futuro. La izquierda tiene como tarea, en consecuencia, proporcionar un télos, y si éste no pasa por la utopía largoplacista, debe pasar por el reformismo (Clark, 2012, 65). Ahora bien, proponer el reformismo entraña el abandono de la revolución, otro de los pilares sobre los que se asienta el marxismo, el cual, pese a haber captado brillantemente las creencias y prácticas de la sociedad burguesa del siglo XIX, no entendió correctamente su fin (Clark, 2012, 54). Marx creyó que el colapso social vendría por una aceleración de los poderes productivos capitalistas, cuando realmente las distintas crisis se fueron solventando gracias al poder camaleónico del sistema. Tanta mutación no transformó el sistema radicalmente mediante una revolución, sino que lo fue transformando hasta convertirlo en una farsa, una comedia tétrica en la que nada era lo que parecía. El estalinismo, el nacionalsocialismo, las operaciones condor, los 
polpots y pinochets que protagonizaron la historia, probaron sangrientamente - dice Clark - que la válvula de escape que era la revolución era una quimera sin sentido. Todas estas tragedias, surgidas de la barbarie humana, llevan al crítico inglés a abandonar el partido de la revolución y la utopía.

Clark solventa la dificultad de proponer una sociedad más justa mediante el reformismo recurriendo a un Nieztsche "moderado" (Clark, 2012, 60, el texto que se cita corresponde a la La voluntad de poder), quien vaticina que, a través del humilde, del prudente, de aquel "que admite [...] una verdadera cantidad de contingencia y absurdo [...] sin volverse ellos mismos pequeños y débiles", la humanidad alcanzará la "fortaleza" real. Podría ser que para el Nietzsche clarkiano, visto desde este curioso punto de vista tan alejado del martillazo como método, la muerte de Dios sea una especie de proceso infinito contra la injusticia y contra las políticas que la sustentan y que, a día de hoy, ganan claramente el partido. Así lo expresa el crítico británico:

[la izquierda debe formular] una política que diga inequívocamente: "La paz nunca se alcanzará". No está en la naturaleza de los asuntos (humanos) que deba alcanzarse. Pero ese reconocimiento, para la izquierda, sólo hace más esencial -y cuanto más esencial, más revolucionario el programa- que el foco, el siempre recurrente centro de la política, deba ser el contener los efectos y el alcance de la guerra, e intentar (la demanda revolucionaria más profunda) valorar la agresividad y la territorialidad separada de su forma de Estado-nación. Pieza por pieza; contra la corriente; interminablemente. Con el mismo espíritu de una izquierda que pudiera centrarse de nuevo en el problema de la pobreza (Clark, 2012, 66).

La propuesta es en apariencia contradictoria, porque debe conjugar el télos, que normalmente se asocia con el futuro, con el anclaje en el presente. Pero es esa precisamente la clave: el télos es el presente, el combate diario, la deconstrucción infinita, juntar grano a grano de arena para conseguir construir algo mejor. Ir más allá del combate diario con la injusticia presente, sin tener en cuenta nuestra barbarie constitutiva, supone que todo el castillo de naipes teórico que debemos construir para llegar a la utopía se nos derrumbe en cualquier momento. Por eso podemos decir con Clark que el reformismo, en el fondo, es actualmente el único modo de implementar una verdadera revolución (Clark, 2012, 65), porque sólo así se puede cambiar el ethos político hodierno.

Resulta ciertamente desconcertante que la respuesta desde la izquierda de R. Williams al pesimismo elitista de Steiner haya derivado, a través de Eagleton y Clark, en otro tipo de pesimismo, aunque el de este último en un sentido más ontológico que el cultural de Steiner. Es como si no hubiera posibilidad de escapatoria. Aun así, parece justo defender la postura del historiador del arte británico, porque, a nuestro juicio, recoge una crítica a la modernidad basada en una realidad (la barbarie o maldad humana) que vemos reflejada a diario en las distintas tragedias del mundo. Un verdadero pesimismo consistiría en olvidarse por completo de la revolución y la utopía. Pero no es ese el mensaje de Clark, como podría parecer en una lectura apresurada, sino más bien el contrario. 
En realidad, lo que propone es que la verdadera revolución consiste en dar numerosos pequeños pasos: es cierto que no vamos a llegar a ninguna tierra prometida -esa sería la metáfora de la utopía-, pero el acto mismo de luchar por no quedarnos inmóviles (a pesar de nuestra tendencia a la crueldad) es la tarea necesaria para la construcción de una nueva política. La labor de la tragedia, en consecuencia, es hacernos entender nuestra propia naturaleza y, partiendo de ese conocimiento, actuar políticamente en el presente. En ese sentido afirma Clark que "no hay futuro", sólo hay ahora. El futuro de la izquierda se debe resolver en el aquí y en el ahora, esa es la visión alternativa de la revolución en el presente.

\section{Conclusión}

En el presente ensayo hemos intentado mostrar la relación entre tragedia y política, en concreto entre tragedia y revolución. Para ello, y para captar la profundidad del debate en su justa medida, en primer lo contextualizamos desde el punto de partida que supone tesis de Steiner sobre la muerte de la tragedia.

R. Williams fue quien entendió que la idea de Steiner no era simplemente parte de un estudio literario, porque la tragedia no es simplemente un género literario. La tragedia no es cosa de electras y romeos, sino que la vemos con nuestros propios ojos. Eagleton partirá de esta crítica de su maestro R. Williams a Steiner, pero sin su humanismo de raíz ilustrada. Cree que la injusticia es combatible y que la revolución, que es la lucha por un orden más justo, es un objetivo lícito y necesario. Pero se distancia de su mentor en el optimismo irrestricto: lo Real nos habla desde lo más oscuro del ser humano, y no prestar atención a esa parcela supone una falta de realismo que no puede sino tener una influencia negativa en la elaboración de políticas reales destinadas a combatir las injusticias. Esa negatividad la encontraremos, precisamente, en las víctimas de la injusticia, el pharmakos.

Podríamos decir que, tanto en Eagleton como en Williams, se puede ver, al contrario que en Steiner, la postura que entiende la política de la tragedia. Efectivamente, para ellos, aunque de distintas maneras y con profundidad desigual, la tragedia es un arma política y revolucionaria. Clark discrepa de la idea de revolución como logro futuro, tal y como los dos autores anteriores la entienden. Clark defiende que un orden social más justo debe ser construido mediante la consecución de pequeños objetivos cotidianos, ya que, si no procedemos de ese modo, las limitaciones de la naturaleza humana (violencia y barbarie) acabarán con el proyecto de izquierda como han acabado con las utopías del siglo anterior, esto es, finalizarán en el inmovilismo y el infantilismo. Su realismo, a fin de cuentas, se sintetiza en un cambio radical del aquí y ahora, y pone en cuestión las bases mismas de la acción de la izquierda trasformadora en la actualidad. En definitiva, lo trágico es, en eso sí que coinciden los tres intelectuales -y por eso debemos subrayarlo-, algo con lo que convivimos y que no podemos eludir para intentar construir una sociedad más justa.

\section{Bibliografía}

ARISTÓTELES (2007). Poética, Madrid: Biblioteca Nueva. CHEJOV, A. (2017). Teatro completo. Barcelona: Losada. 
CLARK, T. J. (2012): "Para una izquierda sin futuro". New Left Review, (Marzo- Abril, 2012).

CRITCHLEY, S. (2014). Tragedia y modernidad, (Ed.) Ramón del Castillo. Madrid: Trotta. DEL CASTILLO, R. (2014). “Un filósofo con mano izquierda.” En Critchley, S. Tragedia y modernidad, Madrid: Trotta.

DEL CASTILlO, R. (2013). "No nos pongamos trágicos.” En Cano, G., Maura, E., Moya, E. (Eds.). Consideraciones intempestivas. En torno a Jacobo Muñoz, Madrid: Biblioteca Nueva.

EAGLETON, T. (2003). Sweet Violence. The Idea of the Tragic, Oxford: Blackwell Publishing. Edición en castellano (2011). Dulce violencia. La idea de lo trágico, Madrid: Trotta.

EAGLETON, T. (2010). Los extranjeros. Por una ética de la solidaridad, Barcelona: Paidós. LACAN, J. (1990). Ética del psicoanálisis, Buenos Aires: Paidós.

IBSEN, H., (2007). Casa de muñecas. Barcelona: Losada.

REHM, R. (2003). Radical Theatre: Greek Tragedy and the Modern World, Londres: Duckworth.

STEINER, G. (1978). The Death of Tragedy, London: Faber and Faber. Edición en castellano (2012). La muerte de la tragedia. Madrid: FCE/Siruela

STEINER, G. (1991). El castillo de Barbazul. Aproximación a un nuevo concepto de cultura, Barcelona: Gedisa.

STRINDBERG, A., (2012). Los camaradas y otras obras. Barcelona: Losada.

VERNANT, J. P., VIDAL-NASQUET, P. (1981). Tragedy and Myth in Ancient Greece, Sussex: Harvester Press. Edición en castellano (2002). Mito y tragedia en la Grecia Antigua. Barcelona: Paidós.

WALlACE, J. (2007). The Cambridge Introduction to Tragedy. Cambridge: Cambridge Press.

WILLIAMS, R. (1969). Modern Tragedy, London: Chatto and Windus. Edición en castellano (2014). Tragedia moderna, Buenos Aires: Edhasa. 